\title{
Zooplankton metabolism in South African estuaries: does habitat type influence ecological strategies?
}

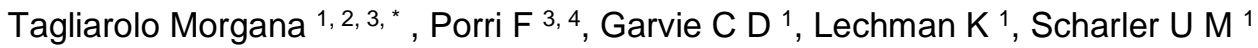

${ }^{1}$ School Of Life Sciences, University Of Kwazulu-Natal, Westville Campus, University Road, 3629

Durban, South Africa

2 Ifremer, Umsr Leeisa (Cnrs, Ug, Ifremer), Centre De Recherche De Montabo, 275 Route De Montabo, 97300 Cayenne, France

${ }^{3}$ South African Institute For Aquatic Biodiversity, Private Bag 1015, 6140 Grahamstown, South Africa

${ }^{4}$ Rhodes Department Of Zoology And Entomology, Rhodes University, Barratt Complex, African St, Grahamstown 6140, South Africa

*Corresponding author : Morgana Tagliarolo, email address : morgana.tagliarolo@gmail.com

\begin{abstract}
:
Zooplankton community composition, biomass and metabolism can vary drastically over space and time in subtropical estuaries. Changing environmental conditions can affect communities differently, depending on the characteristics of the species involved. In the present study, we compared the rates of oxygen consumption of the dominant zooplankton taxa living in permanently open and in temporally open/closed estuaries. The metabolic response was tested at four temperatures experienced by the animals in their natural environment. Zooplankton from the temporally open/closed estuary showed low activation energies and low rate of metabolism at the highest temperature tested. Animals from the permanently open estuary had higher respiration rates at increased temperatures than those from the open/closed counterpart, with one taxon showing a particularly strong response to temperature increase. Results suggest that the metabolism of zooplankton in subtropical estuaries can be influenced by the environmental conditions experienced and those characteristics need to be accounted for in the development of bioenergetics budgets of species and ecosystems.
\end{abstract}

Keywords : metabolism, zooplankton, respiration, estuary, thermal sensitivity 


\section{Introduction}

Ecosystem functioning is directly influenced by the composition of its communities and by the functional traits (e.g. metabolism, growth, reproduction strategy) of the different organisms (Hébert et al., 2015). Life-history strategies of organisms living in a specific habitat are shaped to enable individuals to cope with the spatial and temporal variability of their present environment (Blanck et al., 2007).

Environmental conditions may thus evolutionary drive the occurrence of particular functional traits and species presence/absence at a site. Studies on terrestrial primary producers showed that their physiological traits (such as nitrogen cycling rates and growth rate) can strongly affect ecosystem resistance and resilience (Diaz and Cabido, 2001). The functional traits of marine and freshwater zooplankton have important implications for carbon storage and energy fluxes (Hébert et al., 2015). In turn, functional traits themselves are affected by changing environmental conditions, ultimately influencing communities (Edwards et al., 2013).

Despite that many factors (environment variability, species traits and performances) can influence the community structure, some of them are less predictive than others (McGill et al., 2006). Among the various environmental variables, temperature is between the most relevant in influencing fitness, growth and metabolic rates of ectothermic animals (Folguera et al., 2011). Numerous traits have been used in the literature to link the performance and behaviour of zooplankton to community and ecosystem processes, but respiration is considered one of the best suited quantitative candidates for zooplankton (Hébert et al., 2017, 2016; Wooldridge, 1999). Respiration rates are significantly influenced by temperature and relate to several organismal functions such as growth, feeding and reproduction rates (Rinke and Vijverberg, 2005).

Environmental temperature changes can therefore affect not only the metabolism of single individuals, but also the intricate ecosystem dynamics (Cross et al., 2015).

A trait-focused approach is generally suggested when investigating the mechanism underlying the presence of specific communities at particular sites (McGill et al., 2006). Species co-occurrence in specific habitats suggests the existence of a repeated evolutionary mechanism relating community to environmental features. Identifying the relationships between the functional traits and the environmental gradients can therefore help in detecting general patterns valid in specific areas and making predictions therein (McGill et al., 2006). For instance, the relationship between specific local environmental characteristics and morphological and behavioural functional traits estimated in French streams has been proven valid for different continents (Lamouroux et al., 2002). Although community diversity is relatively easy to measure, the morphological, physiological and behavioural characteristics of the different species are still 
poorly considered in aquatic ecosystem studies since measurements are generally complicated.

In tropical and warm-temperate estuarine regions, zooplankton community compositions and biomass can vary drastically over short time periods due to changes in environmental conditions, and top-down and bottom-up pressures in their food webs (Froneman, 2004; Hoover et al., 2006). In temporarily open/closed estuaries (TOCEs), mouth breaching and prolonged closures are additional factors contributing to changes in communities (Whitfield et al., 2012). In general, few taxa dominate the estuarine mesozooplankton community which persist in the estuarine system even during extreme environmental changes (Deale et al., 2013; Duggan and White, 2010; Jerling and Wooldridge, 1995a; Kibirige et al., 2006; Rissik et al., 2009; Salvador and Bersano, 2017). The variability of the physical and chemical environment of South African estuaries is dependent on river flow and sedimentary conditions of the mouth, and different abundances and dominant species may therefore be found in estuaries with different physico-chemical characteristics (Cooper, 2001; Jerling and Wooldridge, 1995b; Kibirige and Perissinotto, 2003; Schlacher and Wooldridge, 1996; Whitfield and Baliwe, 2013; Wooldridge and Callahan, 2000).

In estuarine food webs, zooplankton communities occupy a central position, linking low to high tropic levels (Sterner, 2009), and pelagic with benthic habitats through their diel migrations. Zooplankton communities influence the biomass and the community structure of their prey and predators as well as control several nutrient cycles (Boyce et al., 2015; Pace et al., 1999; Sailley et al., 2015). Only a handful of studies is available on the eco-physiology of subtropical zooplankton, with a general focus on their size classes rather the distinct taxonomic groups, due to the difficulty of working on small individuals (Carrasco et al., 2013, 2007; Harrison et al., 2001; Jerling and Wooldridge, 1995b). Amongst the several parameters affecting the energy consumption of planktonic copepods, body weight, temperature and motion behaviour have been highlighted as important (Paffenhöfer, 2006).

In this study, we investigated the effect of different environmental conditions, specifically that of estuarine thermal dynamics, on the respiration rates of the dominant zooplankton species at the time. We hypothesised that the different thermal conditions found in the two estuaries shape the metabolic responses of organisms that allows them to cope with their current habitat.

\section{Material and methods}

Sampling sites and environmental parameters

Zooplankton specimens were collected from two estuaries located to the north of Durban, on the KwaZulu-Natal coast, South Africa (Fig. 1). The two estuarine 
systems differ especially in their mouth status. In Mdloti Estuary $\left(29^{\circ} 38^{\prime} \mathrm{S}\right.$, $31^{\circ} 08^{\prime} \mathrm{E}$ ), prolonged periods of inlet closure have been recorded, whereas Mlalazi Estuary ( $\left.28^{\circ} 56^{\prime} \mathrm{S}, 31^{\circ} 48^{\prime} \mathrm{E}\right)$ is a permanently open system, closed only during major droughts (Hill, 1966; Stretch and Zietsman, 2004).

Temperature and salinity were monitored for a year (from the beginning of January to the end of November 2017) at two locations within each estuary (Fig. 1). At each location, an Odyssey (Dataflow Systems PTY Limited, Christchurch, NZ) data logger was set to record temperature and conductivity every 30 minutes. Conductivity measurements were converted to PSU following Fofonoff and Millard (1983). At Mdloti, the probe was removed from the site following each mouthbreaching event and was redeployed as soon as the water level had increased sufficiently to submerge the probe.

Zooplankton sampling and respiration measurements

Zooplankton communities living in Mdloti and Mlalazi estuaries were characterised by a previous project performing monthly sampling in the lower, middle and upper reaches between July 2014 and June 2016 (unpublished data). This monitoring programme acquired daytime samples with a hyperbenthic sled (200 $\mu \mathrm{m}$ mesh) and a standardised subsampling protocol was employed for enumeration of mesozooplankton densities (Jerling and Wooldridge, 1995a). Taxa were identified to the lowest practical taxonomic units.

Results showed that several zooplankton taxa were present at Mdloti (63) and Mlalazi (72) estuaries, but the communities were often dominated by a single taxon. Species of Ceriodaphnia (Ceriodaphnia rigaudi and Ceriodaphnia reticulata) and Cyclopoida (Thermocyclops sp. and Mesocyclops sp.) were the prominent taxa in the mesozooplankton community of Mdloti. The persistence of oligohaline conditions (between 2014 and 2016) within the system promoted the development of these freshwater groups. In Mlalazi, the calanoid copepods, Acartiella natalensis and Pseudodiaptomus spp. were the most prevalent zooplankters, most likely supported by the permanent poly- to mesohaline conditions.

Zooplankton specimens were collected from the lower reaches from the Mdloti Estuary (27 July 2016) and from the Mlalazi Estuary (31 March 2017) using a

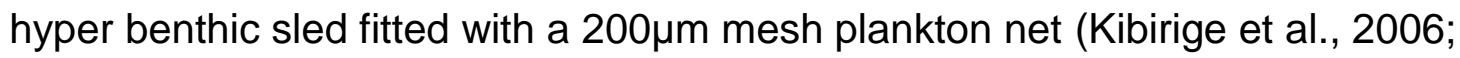
Thomas et al., 2005). Environmental conditions in the surface water of the lower reaches of Mlalazi and Mdloti estuaries during sampling in July 2016 and March 2017 were of $16.2 \pm 0.4{ }^{\circ} \mathrm{C}$ and $0.5 \pm 0.0$ salinity and of $24.8 \pm 1.1^{\circ} \mathrm{C}$ and $47.0 \pm$ 7.3 salinity respectively.

Animals were transported to the laboratory at the University of KwaZulu-Natal (Durban) where they were manually sorted under a stereomicroscope (Fig. 2) to isolate the two selected taxa per estuary (Ceriodaphnia spp. and Cyclopoida for Mdloti Estuary and Pseudodiaptomus spp. and Acartiella natalensis for Mlalazi 
Estuary). After sorting (around 300 individuals per taxon), to allow for recovery from sampling stress, specimens were kept for one day in $500 \mathrm{ml}$ containers filled with filtered $(200 \mu \mathrm{m}$ mesh) natural estuarine water (collected at the sampling site), with a maximal density of 60 individuals per litre. Animals were then transported by air $(<5 h)$ to the Aquatic Ecophysiology Research Platform (hereafter, AERP) at the South African Institute for Aquatic Biodiversity (Grahamstown, South Africa). At the AERP, animals were acclimated to four experimental thermal conditions $\left(15^{\circ} \mathrm{C}, 20^{\circ} \mathrm{C}, 25^{\circ} \mathrm{C}\right.$ and $\left.30^{\circ} \mathrm{C}\right)$ for 3 days. Water was partially changed (20\%) every second day and animals were fed ad libitum with aquarium fish food. During transport, few containers showed high mortality rates probably due to water contamination or waste accumulations, and all animals housed in those containers were discarded.

Experiments were performed between the $2^{\text {nd }}$ and the $4^{\text {th }}$ of August 2016 for Mdloti and the $8^{\text {th }}$ and $9^{\text {th }}$ of April 2017 for Mlalazi. Respiration rates were measured individually with optical fluorescence-based oxygen meters (Sensor dish reader SDR2 and Fibox 4, Presens, Germany) in static respirometry chambers filled with artificial water at the same salinity as recorded at the sampling sites. During the measurements, an individual lid closed each chamber, no food was available, and the animals were kept in the dark. The results can therefore be approximated to the resting metabolic rate (Clarke, 2004).

Individuals were enclosed in a 24-chamber, $200 \mu \mathrm{l}$ well glass multiplate and after a 10 minutes acclimation period, oxygen concentration in the incubation chambers was recorded $\left(\mathrm{mg} \mathrm{l}^{-1}\right)$ at 30 -s intervals for approximately 90 minutes ( $\pm 10 \mathrm{~min}$ ). Oxygen consumption was calculated as the linear slope of the change in $\mathrm{O}_{2}$ over time during the incubation period (all linear regressions were significant $p<0.0001)$. Respiration rates were corrected against the control chamber filled with artificial water (four control chambers for each glass multiplate).

At the end of each experimental trial, each individual was preserved separately in $10 \%$ formalin for further biometric measurements. The volume of individuals was estimated to correct for the incubation chamber volumes for the calculation of the individual oxygen consumption rate. Individual length (L) and width (W) were measured under a microscope (ZEISS V12) and individual pictures were taken to allow for a double identification confirmation. The geometric volume $(\mathrm{V})$ (Hillebrand et al., 1999) of each animal was estimated from the formula for a ellipsoid, $V=\frac{4}{3} \pi a b c$, where a represents the length axis and $b$ and $c$ were approximated to be equal to the width axes.

Due to the small size of the specimens $(<1 \mathrm{~mm})$ and the relative difficulty in weighing single individuals (Culver et al., 1985), an average individual dry weight (DW) was estimated by oven drying $\left(60^{\circ} \mathrm{C}\right.$ for $\left.6 \mathrm{~h}\right)$ a minimum of 150 individuals of each taxon sampled at the same sites during the same year. Average DW was used to calculate the mass corrected respiration rates. 


\section{Statistical analysis}

Daily salinity and temperature amplitude were calculated as a difference between the daily maximal and the minimal daily value recorded at each site. Differences in daily variability between sites were tested by using a one-way ANOVA with Welch correction for unequal variance for both salinity and temperature.

Respiration rates of the different taxa were compared by using two statistical approaches. Firstly, the log transformed respiration rates (to ensure the homogeneity of variance) were compared among taxa and temperatures by applying a type III ANOVA for unbalanced design. Secondly, a mass correction was applied following:

$$
R=M^{b}
$$

where $\mathrm{R}$ is the respiration rate $\left(\mu \mathrm{mol} \mathrm{O} \mathrm{O}^{-1}\right.$ animall $\left.{ }^{-1}\right), \mathrm{M}$ is the body mass and $\mathrm{b}$ is the mass scaling exponent. The mass scaling exponent (b) was calculated on the entire data set accordingly to the general theory of Gillooly et al. (2001) assuming that metabolic rate scales to body mass and temperature following the logtransformed linear model:

$$
\ln (R)=\ln a+b[\ln (M)]+E\left(\frac{1}{k T}\right)
$$

where $\mathrm{a}$ is the taxon-specific normalization constant, $\mathrm{E}$ is the activation energy, $\mathrm{k}$ is the Boltzmann constant $\left(8.62 \times 10^{-5} \mathrm{eV} \mathrm{K}^{-1}\right)$ and $\mathrm{T}$ is the body temperature in Kelvins (or water temperature for aquatic invertebrates).

In order to compare the respirometric response of the different taxa to increasing temperature, an analysis of covariance (ANCOVA) was performed on the linearised Arrhenius plots (Arrhenius, 1889) that were calculated from the masscorrected respiration rates (Gillooly, 2001; Tagliarolo et al., 2018). The homogeneity of slope was confirmed first ( $p$ (interaction) $=0.12$ ). The ANCOVA test was performed by using temperature as a continuous predictor and taxa or estuary as a categorical predictor with a type III regression for unbalanced data. All analyses were performed using $\mathrm{R}$ (car, agricolae, Ismeans packages).

\section{Results}

\subsection{Environmental data}

At Mdloti, three breaching events occurred during the recording period (February, May and October 2017). However, salinity did not increase substantially, reaching its highest value of 4 in April 2017 (Fig. 3).

Temperature and salinity in Mlalazi Estuary were highly variable and showed values higher than Mdloti Estuary (Fig. 4, Table 1). The analysis of the daily temperature and salinity variations showed that the amplitude of the daily 
variation of both variables was significantly higher at Mlalazi than Mdloti (one-way ANOVA for temperature, $F=152, p<0.001$, d.f. $=3$, one-way ANOVA for salinity, $F=450, p<0.001$, d.f. $=3$, Fig. 5).

Zooplankton physiology

The individual size and biomass varied between the studied taxa: the smaller individuals in length and biomass were Acartiella natalensis and Ceriodaphnia spp. and the larger specimens were Pseudodiaptomus spp. and Cyclopoida (Table 2). The respiration rates of individuals acclimated to temperatures ranging from 16 to $30^{\circ} \mathrm{C}$ varied between 0.12 and $22.3 \mathrm{mmol} \mathrm{O}_{2} \mathrm{~h}^{-1}$ ind $^{-1}$ and between 0.047 and $3.785 \mu \mathrm{mol} \mathrm{O}_{2} \mathrm{~h}^{-1} \mathrm{mgDW}^{-1}$ and was comparable to literature values (Annex 1). Respiration rate of Pseudodiaptomus spp. was significantly higher than that of the other species except Ceriodaphnia spp. (ANOVA, $F=11.50, p<0.001$, HSD Tukey's Post hoc test, $p<0.05$ ).

The respiration rate of all taxa except Cyclopoida increased from the lowest to the highest temperature (Fig. 6). The fitting of the general equation from Gillooly et al. (2001) to the entire dataset was significant $(F(2,194)=7.95, p<0.001)$ and the empirically calculated mass scaling exponent was 0.43 (standard error $=0.17$, $\mathrm{p}<0.05)$.

To compare the response to temperature changes among taxa, the respiration rates were mass corrected using the coefficient of 0.43 and the relationship was expressed by calculating the Arrhenius plot for each species (Fig. 7, Table 3). Since a metabolic depression was evident for Cyclopoidae at $30^{\circ} \mathrm{C}$, the Arrhenius plot was calculated for the data points measured at temperatures from 15 to $25^{\circ} \mathrm{C}$. Despite a lower activation energy measured for Cyclopoida and a steeper slope for Pseudodiaptomus spp., ANCOVA did not show statistical differences between the taxa $(F=0.37$, d.f. $=3, p=0.77)$ or estuarine systems $(F=0.03$, d.f. $=1, p=0.87$ ).

\section{Discussion}

Respiration rates of zooplankton are affected by a multitude of environmental and biological factors (e.g. activity level, migration, developmental stage) (Schukat et al., 2013). For poikilotherm animals like zooplankton, metabolic rate is expected to increase with increasing temperature following the Arrhenius law and to vary with body weight following the general scaling law (Almeda et al., 2011). The mass scaling exponent can vary significantly among taxonomic groups and it is often inconsistent with the values suggested by the universal scaling law for metabolism rates (Glazier, 2006; Hernández-León and Ikeda, 2005; Kiørboe and Hirst, 2014; Kolokotrones et al., 2010). When comparing intra- and interspecific metabolic rates, the assumption of a common scaling exponent for mass across species is necessary to compensate for the different sizes. In order to compare the respiratory responses to temperature changes of main zooplankton taxa recorded in South African subtropical estuaries, a common mass scaling 
exponent was estimated on the entire data set $(n=197$, mass scaling exponent $=$ 0.43). Several anomalous size scaling relationships have been previously recorded in small organisms and it is not surprising to find values different from the theoretical universal values due to the influence of several intrinsic and extrinsic factors (Glazier, 2005; Kiørboe and Hirst, 2014). Several authors have abandoned the theory of a unique mass-scaling exponent since a number of interspecific biological processes can justify a significant deviance from the canonical $3 / 4$ value (Alcaraz, 2016). In our study, the calculated exponent differed from previous estimations performed on other zooplankton species possibly due to differences in interspecific metabolism, to the small size range of individual organisms used in our sample $(0.18-1.20 \mathrm{~mm})$ and perhaps a too coarse approximation of individual biomass due to employing an average (Glazier, 2005; Ikeda, 1985). Energy allocation may differ among species due to different feeding modes, body types and life modes, leading to different allometric coefficients (Kiørboe and Hirst, 2014). The scaling to body mass for zooplankton feeding in natural seawater has been shown to have a much lower slope compared to individuals fed with laboratory cultured food, probably due to food limitations (Saiz and Calbet, 2007). The three-quarter law has been therefore considered as the upper bound which is rarely achieved in nature (Saiz and Calbet, 2007). Using an estimated scaling exponent instead of the traditional $3 / 4$ value is considered the best approach to estimate activation energies (Downs et al., 2008).

Considering the size ranges in our study, it was apparent that the respiration rates of all four zooplankton taxa were influenced by temperature. Despite that, the analysis of covariance on the mass corrected rates did not show any significant difference between the studied taxa, probably due to high inter-individual variability. Respiration rates were significantly highest for Pseudodiaptomus spp. than for the other taxa except for Ceriodaphnia spp.. Pseudodiaptomus spp. also showed the stronger response to temperature changes (high activation energy of $0.99 \mathrm{eV}$ ), suggesting that this species can easily adapt their metabolism to highest temperatures without any need for metabolism suppression.

Temperatures measured at the Mlalazi Estuary reached $25^{\circ} \mathrm{C}$ and above a considerable number of times, which implies that Pseudodiaptomus spp. could take advantage of the high range of temperatures to accelerate its metabolism to grow and reproduce faster than the other species. This metabolic advantage can be a hindrance in a nutrient limited habitat, the Mlalazi Estuary is however generally a food-rich system (Ortega-Cisneros and Scharler, 2015). The increased thermal sensitivity (steeper slope), together with its ability to tolerate broad salinity changes and even thrive warmer ecosystems, make Pseudodiaptomus spp. one of the most prolific zooplankton taxa in South African estuaries (Jerling and Wooldridge, 1995a; Wooldridge and Melville-Smith, 1979; Wooldridge, 1999; Wooldridge and Deyzel, 2009). Nevertheless, despite a lack of decrease in metabolism, the steep slope suggests that Pseudodiaptomus spp. is living close to its thermal limits and that any temperature increase can potentially 
cause a stress to this species as already recorded in Malaysia for temperature above $32^{\circ} \mathrm{C}$ (Lehette et al., 2016).

During our study, Pseudodiaptomus spp. was the predominant taxon in Mlalazi, but not in Mdloti, where its densities were less pronounced because of prolonged closure. Although the Mdloti Estuary had started to breach again more frequently in 2017, compared to 2014-2016, Pseudodiaptomus spp. had not yet reestablished itself to become one of the dominant species. Respiration rates of Pseudodiaptomus spp. from the Mdloti Estuary were comparable to the ones measured for the other taxa up to $20^{\circ} \mathrm{C}$. Water temperature in Mdloti was generally lower than in Mlalazi, with an average annual value of around $20^{\circ} \mathrm{C}$. We propose that, due to this generally mild thermal environment, Pseudodiaptomus spp. would have a smaller energetic advantage in Mdloti compared to Mlalazi. Moreover, the increase in metabolic rates at high temperatures requires increased energy uptake which can be a disadvantage at Mdloti, where the particulate organic matter content was at lower levels than in Mlalazi during the study period (Tagliarolo and Scharler, 2018). Due to their wide distribution, it would be interesting to investigate the possible differences in Pseudodiaptomus spp. thermal responses between estuaries with different thermal characteristics. The comparison of the metabolic responses could explain if the thermal response is principally taxa-specific or habitat-specific.

In contrast to Pseudodiaptomus spp., the other studied taxa showed limited or negative sensitivity to temperature. Three of the four studied taxa showed an activation energy value lower than the general interspecific mean activation energy of $0.65 \mathrm{eV}$ (ranging from 0.2 to $1.2 \mathrm{eV}$ ) calculated for aquatic organisms (Brown et al., 2004; Gillooly, 2001), and one taxon (Cyclopoida) displayed a clear reduction of its respiratory abilities at the highest temperature. An alternative physiological mechanism to adapt to elevated temperatures is to reduce metabolic rates to compensate for high maintenance costs (Sokolova et al., 2012). Cyclopoida, collected from the Mdloti Estuary, showed a clear metabolic depression at $30^{\circ} \mathrm{C}$ and their activation energy was lower than the average general 0.6eV (Gillooly, 2001). Temperature at the mouth of the Mdloti Estuary exceeded $25^{\circ} \mathrm{C}$ for only 37 days during the studied period and it never went above $30^{\circ} \mathrm{C}$. Cyclopoida found in Mdloti seemed therefore better adapted to live in cooler waters, but they could still survive the summer peaks (around $28^{\circ} \mathrm{C}$ ) by lowering their metabolism and adopting a compensatory strategy to limit structural damage. Cyclopoida are generally grasp feeders, eating large items such as nematodes, chironomids and larval fish, but diets can also include cladocerans, rotifers, phytoplankton, detritus and bacteria (Nagata and Hanazato, 2006). Their feeding habits can be an additional advantage at Mdloti, since the abundance of small benthic species is higher than at Mlalazi (Tagliarolo and Scharler, 2018).

Limited thermal response was also recorded for the two smaller taxa (Acartiella natalensis and Ceriodaphnia spp.). Acartiella natalensis is very common in South 
African estuaries even at high salinities despite its oligohaline preference (Jones et al., 2016; Wooldridge, 1999). Ceriodaphnia spp. is mostly present in the upper estuarine regions and in freshwater systems (Kibirige et al., 2006). Both taxa seemed to be little influenced by temperature changes and did not show any metabolic failure at increased temperatures.

While temperature and body mass are widely recognised as the most important factors affecting the metabolism of aquatic organisms, several other parameters must be included for the success and persistence of zooplankton species in an ecosystem. All studied species are known to be highly tolerant to salinity changes, but the metabolic activities of the diverse taxa can be differently affected by those variations (Calliari et al., 2006). Moreover, other factors such as water turbidity, interspecific differences in activity level and behavioural characteristics can significantly affect metabolic rates (Bode et al., 2013; Jones et al., 2015). Further studies are still needed to simultaneously assess the effect of multiple stressors on zooplankton and better understand the role of the different taxa for the ecosystem functioning. While respiration rates of all the studied taxa were in the same range and a recovery and acclimation periods were applied, the two different sampling periods could potentially have introduced a bias in the interpretation of the results. Nevertheless, we estimate that the effect is minimal considering the amplitude of the daily temperature variation present at the study sites. Further studies performed seasonally directly on site would however contribute to a better understanding of the fine temporal physiological tuning and adaptation.

Because of their life-strategy, in absence of food limitation, the basal metabolism of zooplankton is relatively high due to the fast growth and reproduction rates (Threlkeld, 1976). Previous studies hypothesised that freshwater species have a higher mass-specific respiration rate than marine animals due to their typical life history strategy to cope with higher temporal instability in food availability and osmotic stress (Hébert et al., 2015). Our results partly confirm such hypothesis since for temperatures below $25^{\circ} \mathrm{C}$ the average mass-specific respiration rates were higher for the two taxa living in the less saline Mdloti. This trend was not recorded for temperatures above $25^{\circ} \mathrm{C}$ since those conditions seemed to be more stressful for Mdloti taxa than for Mlalazi animals.

Our results are particularly relevant as they directly link zooplankton communities to environmental conditions in aquatic ecosystems. Despite that no differences were found at the lower temperatures, animals from TOCEs had the highest mass-specific rates and showed some sign of metabolic depression failure at $30^{\circ} \mathrm{C}$. Conversely, animals from the permanently open estuary had slightly higher rates at increased temperatures. Such dissimilarities must be considered very closely when determining energy budgets especially in a global change context. Nevertheless, future research needs to test if such trait diversity is maintained 
through time, and how additional processes such as trophic interactions can affect those metabolic mechanisms. 


\section{ACKNOWLEDGMENTS}

We would like to thank Ezemvelo KZN Wildlife for their support during fieldwork. Many thanks also to Thembeka Radebe, Kendyl Le Roux and Nicola Carrasco for the help and suggestions. We also would like to acknowledge use of the AERP infrastructure and equipment provided by the South African Institute and the funding channelled through the South African Institute for Aquatic Biodiversity National Research Foundation of South Africa (SAIAB-NRF).

\section{Compliance with Ethical Standards:}

All applicable international, national, and/or institutional guidelines for the care and use of animals were followed. Collection permit from the department of environmental affairs of the Republic of South Africa : RES2016-85.

Ethical approval: Animal Ethics protocol reference number: AREC/083/015PD from the University of KwaZulu-Natal.

\section{Funding}

This work was founded by the UKZN post-doctoral fellowship (granted to M. Tagliarolo) and the National Research Foundation (NRF) travel grant (UID number: 102688) (granted to U. Scharler).

\section{Conflict of interest:}

No conflict interests exist: M. Tagliarolo declare that she has no conflict of interest. F. Porri declare that she has no conflict of interest. U. M. Scharler declare that she has no conflict of interest. K. Lechman declare that she has no conflict of interest. D. Garvie declare that she has no conflict of interest.

\section{Author contributions}

M. Tagliarolo conceived and designed the experiments, performed the experiment, analysed the data and wrote the manuscript. F. Porri wrote the paper and facilitated the laboratory experiments. U. M. Scharler wrote the paper and facilitated the field work. K. Lechman performed the sorting, identification and biomass measurements for Mdloti samples. D. Garvie performed the sorting, identification and biomass measurements for Mlalazi samples.

\section{REFERENCES}

Alcaraz, M. (2016) Marine zooplankton and the metabolic theory of ecology: is it a predictive tool? J Plankton Res. 38: 762-770.

Almeda, R., Alcaraz, M., Calbet, A., and Saiz, E. (2011) Metabolic rates and carbon budget of early developmental stages of the marine cyclopoid copepod Oithona davisae. Limnol Oceanogr. 56: 403-414. 
Arrhenius, S. (1889) Über die dissociationswärme und den einfluss der temperatur auf den dissociationsgrad der elektrolyte. Z Für Phys Chem. 4: 96-116.

Blanck, A., Tedesco, P.A., and Lamouroux, N. (2007) Relationships between life-history strategies of European freshwater fish species and their habitat preferences. Freshw Biol. 52: 843-859. Bode, M., Schukat, A., Hagen, W., and Auel, H. (2013) Predicting metabolic rates of calanoid copepods. J Exp Mar Biol Ecol. 444: 1-7.

Boyce, D.G., Frank, K.T., Leggett, W.C., and Wootton, T. (2015) From mice to elephants: overturning the 'one size fits all' paradigm in marine plankton food chains. Ecol Lett. 18: 504515.

Brown, J.H., Gillooly, J.F., Allen, A.P., Savage, V.M., and West, G.B. (2004) Toward a metabolic theory of ecology. Ecology. 85: 1771-1789.

Calliari, D., Andersen, C.M., Thor, P., Gorokhova, E., and Tiselius, P. (2006) Salinity modulates the energy balance and reproductive success of co-occurring copepods Acartia tonsa and $A$. clausi in different ways. Mar Ecol Prog Ser. 312: 177-188.

Carrasco, N.K., Perissinotto, R., and Jones, S. (2013) Turbidity effects on feeding and mortality of the copepod Acartiella natalensis (Connell and Grindley, 1974) in the St Lucia Estuary, South Africa. J Exp Mar Biol Ecol. 446: 45-51.

Carrasco, N.K., Perissinotto, R., and Miranda, N.A. (2007) Effects of silt loading on the feeding and mortality of the mysid Mesopodopsis africanain the St. Lucia Estuary, South Africa. J Exp Mar Biol Ecol. 352: 152-164.

Clarke, A. (2004) Is there a Universal Temperature Dependence of metabolism? Funct Ecol. 18: 252-256.

Cooper, J.A.G. (2001) Geomorphological variability among microtidal estuaries from the wavedominated South African coast. Geomorphology. 40: 99-122.

Cross, W.F., Hood, J.M., Benstead, J.P., Huryn, A.D., and Nelson, D. (2015) Interactions between temperature and nutrients across levels of ecological organization. Glob Change Biol. 21: 10251040.

Culver, D.A., Boucherle, M.M., Bean, D.J., and Fletcher, J.W. (1985) Biomass of freshwater crustacean zooplankton from length-weight regressions. Can J Fish Aquat Sci. 42: 1380-1390. Deale, M., Perissinotto, R., and Carrasco, N.K. (2013) Recovery dynamics of zooplankton following mouth-breaching in the temporarily open/closed Mdloti Estuary, South Africa. Afr J Aquat Sci. 38: 67-78.

Dıaz, S., and Cabido, M. (2001) Vive la difference: plant functional diversity matters to ecosystem processes. Trends Ecol Evol. 16: 646-655.

Downs, C.J., Hayes, J.P., and Tracy, C.R. (2008) Scaling metabolic rate with body mass and inverse body temperature: a test of the Arrhenius fractal supply model. Funct Ecol. 22: 239-244.

Duggan, I.C., and White, M.A. (2010) Consequences of human-mediated marine intrusions on the zooplankton community of a temperate coastal lagoon. N Z J Mar Freshw Res. 44: 17-28. Edwards, K.F., Litchman, E., and Klausmeier, C.A. (2013) Functional traits explain phytoplankton community structure and seasonal dynamics in a marine ecosystem. Ecol Lett. 16: 56-63. Fofonoff, N.P., and Millard, R.C.J. (1983) Algorithms for the computation of fundamental properties of seawater. (UNESCO Technical Papers in Marine Sciences No. 44). UNESCO, Paris. Folguera, G., Bastías, D.A., Caers, J., Rojas, J.M., Piulachs, M.-D., Bellés, X., et al. (2011) An experimental test of the role of environmental temperature variability on ectotherm molecular, 
physiological and life-history traits: Implications for global warming. Comp Biochem Physiol A Mol Integr Physiol. 159: 242-246.

Froneman, P.W. (2004) Zooplankton community structure and biomass in a southern African temporarily open/closed estuary. Estuar Coast Shelf Sci. 60: 125-132.

Gillooly, J.F. (2001) Effects of Size and Temperature on Metabolic Rate. Science. 293: 2248-2251. Glazier, D.S. (2005) Beyond the : variation in the intra- and interspecific scaling of metabolic rate in animals. Biol Rev. 80: 611.

Glazier, D.S. (2006) The 3/4-Power Law Is Not Universal: Evolution of Isometric, Ontogenetic Metabolic Scaling in Pelagic Animals. BioScience. 56: 325.

Harrison, W.G., Arístegui, J., Head, E.J.H., Li, W.K.W., Longhurst, A.R., and Sameoto, D.D. (2001) Basin-scale variability in plankton biomass and community metabolism in the sub-tropical North Atlantic Ocean. Deep Sea Res Part II Top Stud Oceanogr., JGOFS Research in the North Atlantic Ocean: A Decade of Research, Synthesis and modelling 48: 2241-2269.

Hébert, M.-P., Beisner, B.E., and Maranger, R. (2015) A meta-analysis of zooplankton functional traits influencing ecosystem function. Ecology. 97: 1069-1080.

Hébert, M.-P., Beisner, B.E., and Maranger, R. (2016) A compilation of quantitative functional traits for marine and freshwater crustacean zooplankton. Ecology. Accepted Author Manuscript. Hébert, M.-P., Beisner, B.E., and Maranger, R. (2017) Linking zooplankton communities to ecosystem functioning: toward an effect-trait framework. J Plankton Res. 39: 3-12.

Hernández-León, S., and Ikeda, T. (2005) Zooplankton respiration. In Respiration in Aquatic Systems. Oxford University Press, New York. pp. 57-82.

Hill, B.J. (1966) A contribution to the ecology of the Umlalazi Estuary. Zool Afr. 2: 1-24.

Hillebrand, H., Dürselen, C.-D., Kirschtel, D., Pollingher, U., and Zohary, T. (1999) Biovolume calculation for pelagic and benthic microalgae. J Phycol. 35: 403-424.

Hoover, R., Hoover, D., Miller, M., Landry, M., DeCarlo, E., and Mackenzie, F. (2006) Zooplankton response to storm runoff in a tropical estuary: bottom-up and top-down controls. Mar Ecol Prog Ser. 318: 187-201.

Ikeda, T. (1985) Metabolic rates of epipelagic marine zooplankton as a function of body mass and temperature. Mar Biol. 85: 1-11.

Jerling, H.L., and Wooldridge, T.H. (1995a) Plankton distribution and abundance in the Sundays River estuary, South Africa, with comments on potential feeding interactions. South Afr J Mar Sci. 15: 169-184.

Jerling, H.L., and Wooldridge, T.H. (1995b) Plankton distribution and abundance in the Sundays River estuary, South Africa, with comments on potential feeding interactions. South Afr J Mar Sci. 15: 169-184.

Jones, S., Carrasco, N.K., and Perissinotto, R. (2015) Turbidity effects on the feeding, respiration and mortality of the copepod Pseudodiaptomus stuhlmanni in the St Lucia Estuary, South Africa. $J$ Exp Mar Biol Ecol. 469: 63-68.

Jones, S., Perissinotto, R., Carrasco, N.K., and Vosloo, A. (2016) Impact of a flood event on the zooplankton of an estuarine lake. Mar Biol Res. 12: 158-167.

Kibirige, I., and Perissinotto, R. (2003) The zooplankton community of the Mpenjati Estuary, a South African temporarily open/closed system. Estuar Coast Shelf Sci. 58: 727-741.

Kibirige, I., Perissinotto, R., and Thwala, X. (2006) A comparative study of zooplankton dynamics in two subtropical temporarily open/closed estuaries, South Africa. Mar Biol. 148: 1307-1324. 
Kiørboe, T., and Hirst, A.G. (2014) Shifts in mass scaling of respiration, feeding, and growth rates across life-form transitions in marine pelagic organisms. Am Nat. 183: E118-E130.

Kolokotrones, T., Van Savage, Deeds, E.J., and Fontana, W. (2010) Curvature in metabolic scaling. Nature. 464: 753-756.

Lamouroux, N., Poff, N.L., and Angermeier, P.L. (2002) Intercontinental Convergence of Stream Fish Community Traits Along Geomorphic and Hydraulic Gradients. Ecology. 83: 1792-1807. Lehette, P., Ting, S.M., Chew, L.-L., and Chong, V.C. (2016) Respiration rates of the copepod Pseudodiaptomus annandalei in tropical waters: beyond the thermal optimum. J Plankton Res.

38: 456-467.

McGill, B.J., Enquist, B.J., Weiher, E., and Westoby, M. (2006) Rebuilding community ecology from functional traits. Trends Ecol Evol. 21: 178-185.

Nagata, T., and Hanazato, T. (2006) Different predation impacts of two cyclopoid species on a small-sized zooplankton community: an experimental analysis with mesocosms. Hydrobiologia. 556: 233-242.

Ortega-Cisneros, K., and Scharler, U.M. (2015) Nutrient Dynamics of Estuarine Invertebrates Are Shaped by Feeding Guild Rather than Seasonal River Flow. PLOS ONE. 10: e0137417.

Pace, M.L., Cole, J.J., Carpenter, S.R., and Kitchell, J.F. (1999) Trophic cascades revealed in diverse ecosystems. Trends Ecol Evol. 14: 483-488.

Paffenhöfer, G. (2006) Oxygen consumption in relation to motion of marine planktonic copepods. Mar Ecol Prog Ser. 317: 187-192.

Rinke, K., and Vijverberg, J. (2005) A model approach to evaluate the effect of temperature and food concentration on individual life-history and population dynamics of Daphnia. Ecol Model. 186: 326-344.

Rissik, D., Shon, E.H., Newell, B., Baird, M.E., and Suthers, I.M. (2009) Plankton dynamics due to rainfall, eutrophication, dilution, grazing and assimilation in an urbanized coastal lagoon. Estuar Coast Shelf Sci. 84: 99-107.

Sailley, S.F., Polimene, L., Mitra, A., Atkinson, A., and Allen, J.I. (2015) Impact of zooplankton food selectivity on plankton dynamics and nutrient cycling. J Plankton Res. 37: 519-529.

Saiz, E., and Calbet, A. (2007) Scaling of feeding in marine calanoid copepods. Limnol Oceanogr. 52: 668-675.

Salvador, B., and Bersano, J.G.F. (2017) Zooplankton variability in the subtropical estuarine system of Paranaguá Bay, Brazil, in 2012 and 2013. Estuar Coast Shelf Sci. 199: 1-13.

Schlacher, T.A., and Wooldridge, T.H. (1996) Ecological responses to reductions in freshwater supply and quality in South Africa's estuaries: lessons for management and conservation. $J$ Coast Conserv. 2: 115-130.

Schukat, A., Teuber, L., Hagen, W., Wasmund, N., and Auel, H. (2013) Energetics and carbon budgets of dominant calanoid copepods in the northern Benguela upwelling system. J Exp Mar Biol Ecol. 442: 1-9.

Sokolova, I.M., Frederich, M., Bagwe, R., Lannig, G., and Sukhotin, A.A. (2012) Energy homeostasis as an integrative tool for assessing limits of environmental stress tolerance in aquatic invertebrates. Mar Environ Res. 79: 1-15.

Sterner, R.W. (2009) Role of Zooplankton in Aquatic Ecosystems. In Encyclopedia of Inland Waters. pp. 678-688 Elsevier.

Stretch, D.D., and Zietsman, I. (2004) The hydrodynamics of Mhlanga \& Mdloti Estuaries: Flows, residence times, water levels and mouth dynamics. Water Res Comm Proj K. 5. 
Tagliarolo, M., Porri, F., and Scharler, U.M. (2018) Temperature-induced variability in metabolic activity of ecologically important estuarine macrobenthos. Mar Biol. 165: 23.

Tagliarolo, M., and Scharler, U.M. (2018) Spatial and temporal variability of carbon budgets of shallow South African subtropical estuaries. Sci Total Environ. 626: 915-926.

Thomas, C.M., Perissinotto, R., and Kibirige, I. (2005) Phytoplankton biomass and size structure in two South African eutrophic, temporarily open/closed estuaries. Estuar Coast Shelf Sci. 65: 223238.

Threlkeld, S.T. (1976) Starvation and the size structure of zooplankton communities. Freshw Biol. 6: 489-496.

Whitfield, A.K., and Baliwe, N.G. (2013) A century of science in South African estuaries: Bibliography and review of research trends. South African Institute for Aquatic Biodiversity (SAIAB).

Whitfield, A.K., Bate, G.C., Adams, J.B., Cowley, P.D., Froneman, P.W., Gama, P.T., et al. (2012) A review of the ecology and management of temporarily open/closed estuaries in South Africa, with particular emphasis on river flow and mouth state as primary drivers of these systems. Afr $J$ Mar Sci. 34: 163-180.

Wooldridge, T., and Melville-Smith, R. (1979) Copepod succession in two South African estuaries. J Plankton Res. 1: 329-341.

Wooldridge, T.H. (1999) Estuarine zooplankton community structure and dynamics. Cambridge University Press Cambridge.

Wooldridge, T.H., and Callahan, R. (2000) The effects of a single freshwater release into the Kromme Estuary. 3: Estuarine zooplankton response. Water SA. 26: 311-318.

Wooldridge, T.H., and Deyzel, S.H.P. (2009) Temperature and salinity as abiotic drivers of zooplankton community dynamics in the Great Berg Estuary. Trans R Soc South Afr. 64: 219-237. 


\section{Figures legends}

Fig. 1 Study sites at Mlalazi (ML1 and ML2) and Mdloti (MD1 and MD2) estuaries located in KwaZulu-Natal (South Africa).

Fig. 2 Dominant taxa sampled at Mlalazi and Mdloti estuaries and used for oxygen consumption measurements.

Fig. 3 Temperature and salinity time-series measured at the mouth (MD1) and upstream sites (MD2) at the Mdloti Estuary from January to November 2017. Due to weather or logistic issues, the data set is incomplete (breaks) for some sites and periods.

Fig. 4 Temperature and salinity time-series measured at the mouth (ML1) and upstream site (ML2) at the Mlalazi Estuary from January to November 2017. Due to weather or logistic issues, the data set is incomplete (breaks) for some sites and periods. Please, note the scale difference between the salinity panel in this figure and in figure 3.

Fig. 5 Frequency plot of the temperature and salinity daily amplitude (max-min) in Mdloti (MD) and Mlalazi (ML) estuaries measured at the mouth (1) and upstream (2) from January to November 2017.

Fig. 6 Boxplot of hourly oxygen respiration rates per individual of the four representative taxa, at different temperatures, at the two estuaries, Mdloti and Mlalazi (the box represent the upper and lower quartiles, the line represent the median, the whiskers shows the min and max values ( $1.5^{\star}$ interquartile range) and the dots represents the outliers).

Fig. 7 Temperature dependence of the mass-corrected respiration rates for each taxon. The temperature is expressed as the inverse of absolute temperature $(K)$ multiplied by the Boltzmann's constant $(0.0000862 \mathrm{eV} \mathrm{K}-1)$. The natural logarithm of the mass corrected respiration rate in the $\mathrm{Y}$-axis was calculated by dividing the respiration rate $(\mu \mathrm{mol} \mathrm{O} 2 \mathrm{~h}-1$ animal-1) by the biomass (DW, g) raised to the empirically determined scaling exponent of 0.43 . The grey band around the regression lines represent the $95 \%$ confidence interval. 


\section{Tables}

Table 1 Minimum, median, mean and maximum values for temperature $\left({ }^{\circ} \mathrm{C}\right)$ and salinity recorded for each site from January to November 2017.

\begin{tabular}{|c|c|c|c|}
\hline & & $\begin{array}{l}\text { TEMPERATURE } \\
\left({ }^{\circ} \mathrm{C}\right)\end{array}$ & SALINITY \\
\hline \multirow[t]{2}{*}{ ML } & 1 & $\begin{array}{l}\text { Min: } 15.35 \\
\text { Median: } 22.15 \\
\text { Mean: } 22.49 \\
\text { Max: } 31.66\end{array}$ & $\begin{array}{l}\text { Min: } 0.01 \\
\text { Median: } 27.97 \\
\text { Mean: } 24.28 \\
\text { Max: } 38.20\end{array}$ \\
\hline & 2 & $\begin{array}{l}\text { Min: } 13.16 \\
\text { Median: } 21.52 \\
\text { Mean: } 21.80 \\
\text { Max: } 28.62\end{array}$ & $\begin{array}{l}\text { Min: } 0.03 \\
\text { Median: } 12.03 \\
\text { Mean: } 10.86 \\
\text { Max: } 25.71\end{array}$ \\
\hline \multirow[t]{2}{*}{ MD } & 1 & $\begin{array}{l}\text { Min: } 14.27 \\
\text { Median: } 20.86 \\
\text { Mean: } 20.63 \\
\text { Max: } 27.11\end{array}$ & $\begin{array}{l}\text { Min: } 0.01 \\
\text { Median: } 0.85 \\
\text { Mean: } 1.09 \\
\text { Max: } 4.07\end{array}$ \\
\hline & 2 & $\begin{array}{l}\text { Min: } 13.06 \\
\text { Median: } 21.16 \\
\text { Mean: } 21.30 \\
\text { Max: } 31.05\end{array}$ & $\begin{array}{l}\text { Min: } 0.01 \\
\text { Median: } 0.64 \\
\text { Mean: } 0.78 \\
\text { Max: } 3.23\end{array}$ \\
\hline
\end{tabular}


Table 2 Number of individuals per taxon for each temperature treatment, average individual length and width ( $\mathrm{mm}$ ), and average individual biomass ( $\mu \mathrm{g} D W$ ).

\begin{tabular}{|c|c|c|c|c|c|c|c|c|}
\hline RIVER & SPECIES & $16^{\circ} \mathrm{C}$ & $20^{\circ} \mathrm{C}$ & $25^{\circ} \mathrm{C}$ & $30^{\circ} \mathrm{C}$ & $\begin{array}{l}\text { LENGTH } \\
\text { (MM) }\end{array}$ & $\begin{array}{l}\text { WIDTH } \\
\text { (MM) }\end{array}$ & $\begin{array}{l}\text { BIOMASS } \\
\text { ( } \mu \mathrm{G} \text { DW) }\end{array}$ \\
\hline \multirow{2}{*}{ ML } & $\begin{array}{l}\text { Pseudodiaptomus } \\
\text { spp. }\end{array}$ & 12 & 11 & 15 & 14 & $\begin{array}{l}0.96 \pm \\
0.07\end{array}$ & $\begin{array}{l}0.36 \pm \\
0.04\end{array}$ & $\begin{array}{l}5.90 \pm \\
1.00\end{array}$ \\
\hline & $\begin{array}{l}\text { Acartiella } \\
\text { natalensis }\end{array}$ & 11 & 10 & $\begin{array}{l}\text { No } \\
\text { data }\end{array}$ & 10 & $\begin{array}{l}0.64 \pm \\
0.09\end{array}$ & $\begin{array}{l}0.13 \pm \\
0.05\end{array}$ & $\begin{array}{l}1.60 \pm \\
0.37\end{array}$ \\
\hline \multirow{2}{*}{ MD } & $\begin{array}{l}\text { Ceriodaphnia } \\
\text { spp. }\end{array}$ & 8 & 8 & 12 & 18 & $\begin{array}{l}0.53 \pm \\
0.13\end{array}$ & $\begin{array}{l}0.41 \pm \\
0.11\end{array}$ & $\begin{array}{l}2.61 \pm \\
1.04\end{array}$ \\
\hline & Cyclopoida & 14 & 16 & 19 & 19 & $\begin{array}{l}0.74 \pm \\
0.18\end{array}$ & $\begin{array}{l}0.25 \pm \\
0.07\end{array}$ & $\begin{array}{l}4.11 \pm \\
1.70\end{array}$ \\
\hline
\end{tabular}


Table 3 Parameters for the linear regressions calculated for each taxon between the inverse of absolute temperature $(K)$ multiplied by the Boltzmann's constant $\left(0.0000862 \mathrm{eV} \mathrm{K}^{-1}\right)$ and the natural logarithm of the mass corrected respiration rate [calculated by dividing the respiration rate $\left(\mu \mathrm{mol} \mathrm{O} 2 \mathrm{~h}^{-1}\right.$ animal-1) by the biomass $(D W, g)$ raised to the empirically determined scaling exponent of 0.43$]$.

\begin{tabular}{|l|l|l|l|l|l|}
\hline RIVER & SPECIES & \multicolumn{1}{|c|}{$\mathbf{b}$} & $\mathbf{E}$ & $\mathbf{r}^{2}$ & $\mathbf{p}$ \\
\hline \multirow{2}{*}{ ML } & $\begin{array}{l}\text { Pseudodiaptomus } \\
\text { spp. }\end{array}$ & 35.29 & 0.99 & 0.30 & $>0.0001$ \\
\cline { 2 - 6 } & Acartiella natalensis & 11.14 & 0.38 & 0.13 & $>0.05$ \\
\hline \multirow{2}{*}{ MD } & Ceriodaphnia spp. & 19.67 & 0.59 & 0.20 & $>0.005$ \\
\cline { 2 - 6 } & Cyclopoida & 12.48 & 0.41 & 0.05 & 0.12 \\
\hline
\end{tabular}

$\mathrm{b}$ is the natural logarithm of the taxon-specific normalization constant, $\mathrm{E}=$ activation energy $(e V), r^{2}=$ coefficient of determination, $p=p$-value for the correlation. 

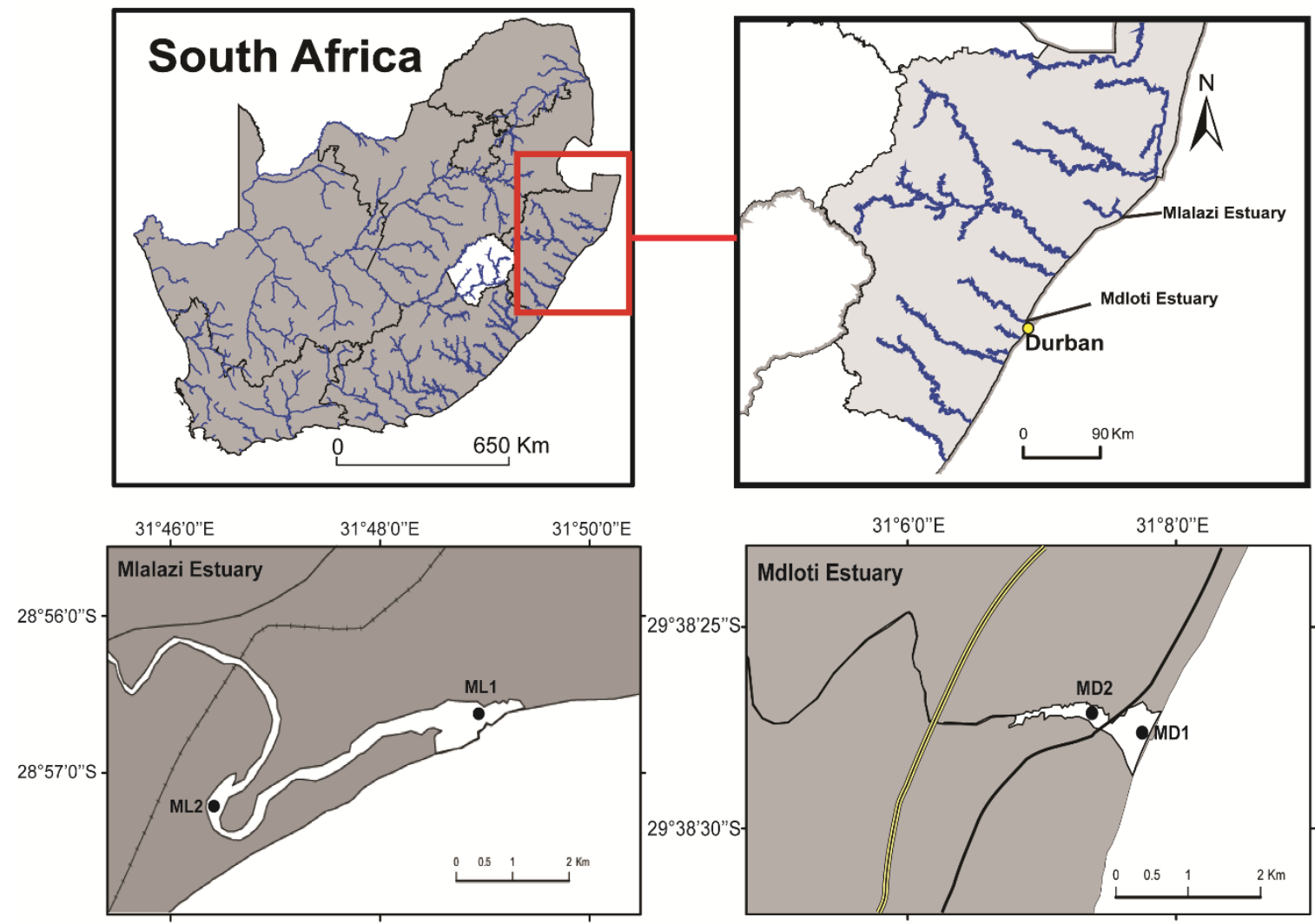

Fig. 1 Study sites at Mlalazi (ML1 and ML2) and Mdloti (MD1 and MD2) estuaries located in KwaZulu-Natal (South Africa). 


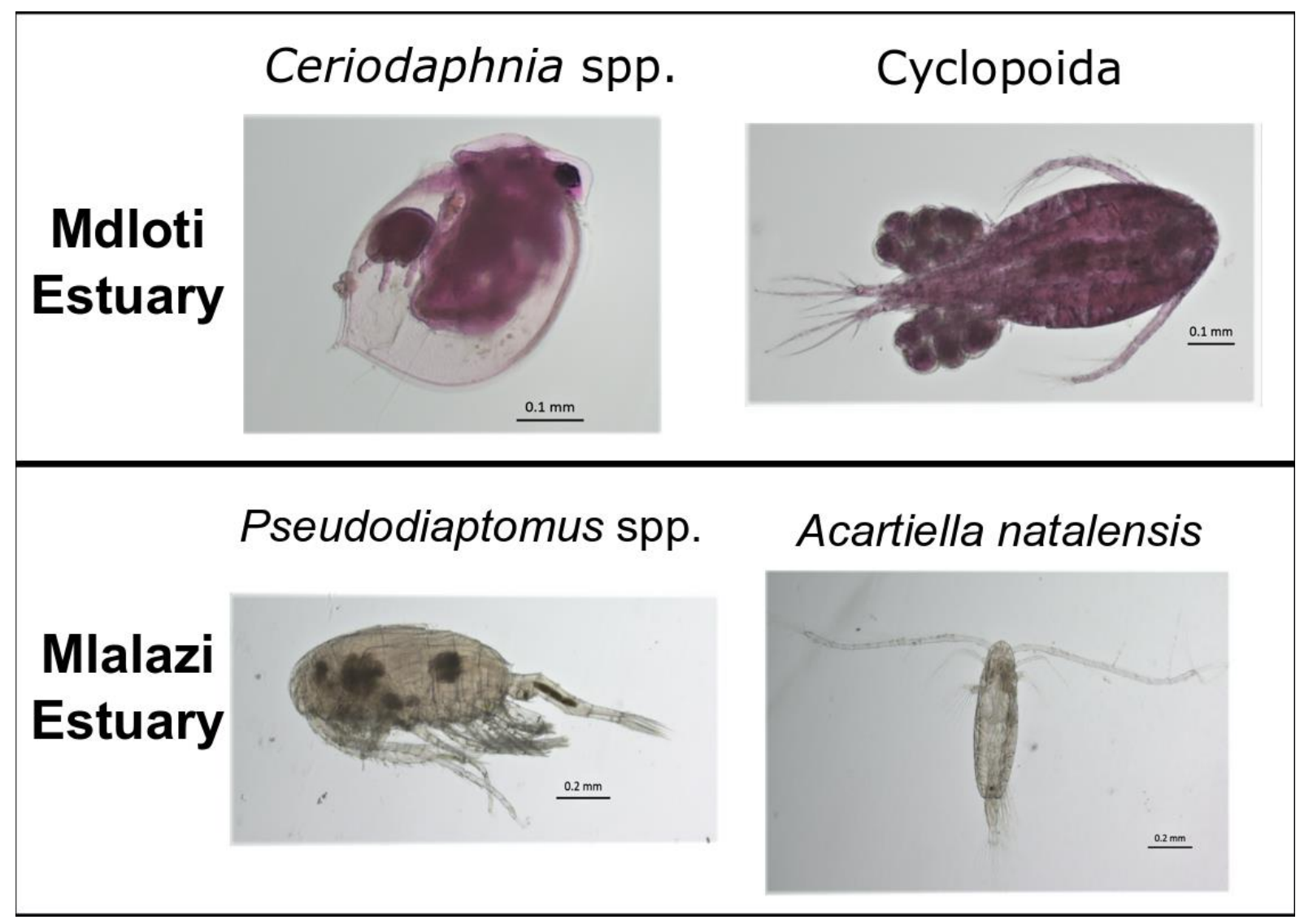

Fig. 2 Dominant taxa sampled at Mlalazi and Mdloti estuaries and used for oxygen consumption measurements. 

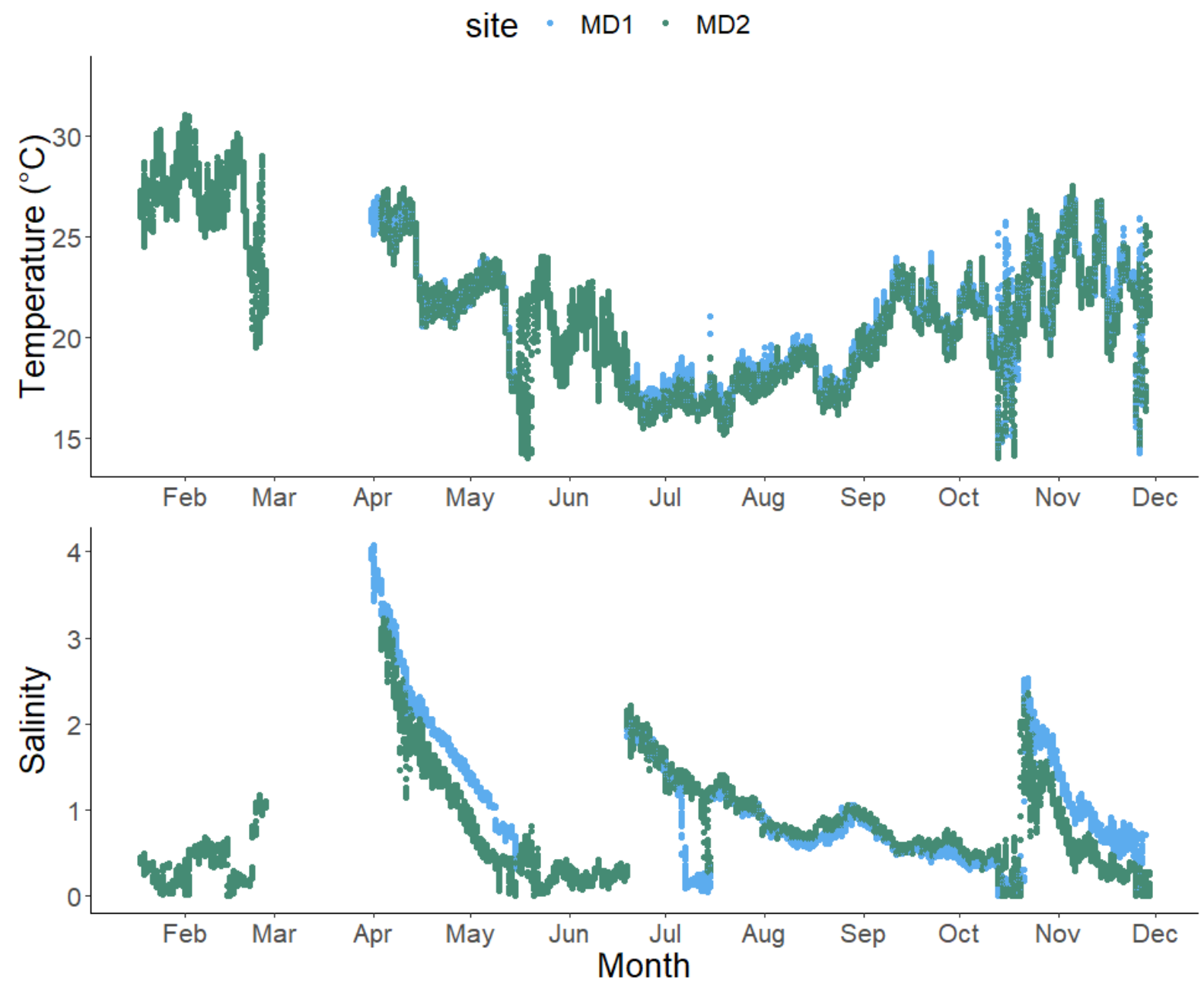

Fig. 3 Temperature and salinity time-series measured at the mouth (MD1) and upstream sites (MD2) at the Mdloti Estuary from January to November 2017. Due to weather or logistic issues, the data set is incomplete (breaks) for some sites and periods. 

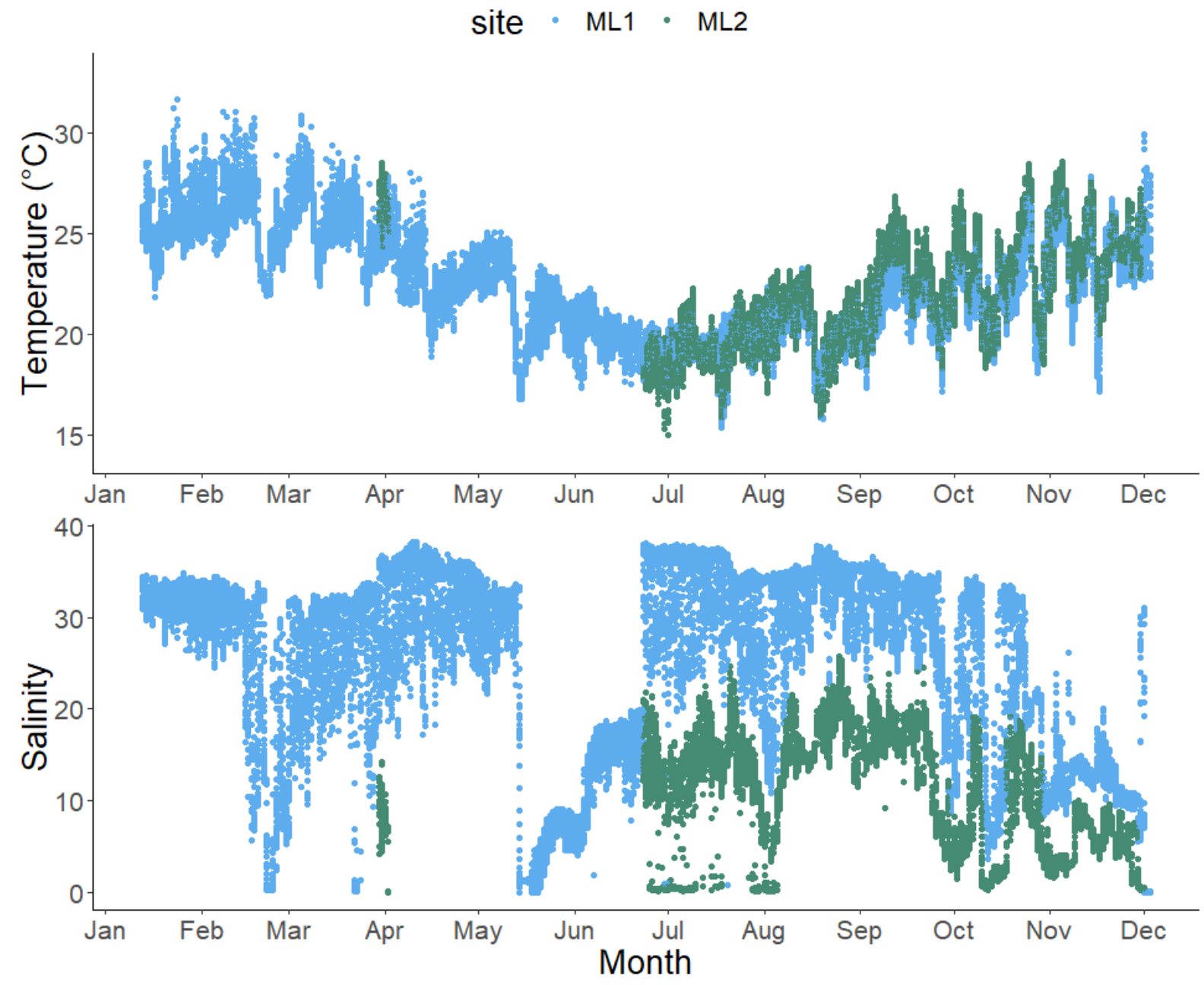

Fig. 4 Temperature and salinity time-series measured at the mouth (ML1) and upstream site (ML2) at the Mlalazi Estuary from January to November 2017. Due to weather or logistic issues, the data set is incomplete (breaks) for some sites and periods. Please, note the scale difference between the salinity panel in this figure and in figure 3. 

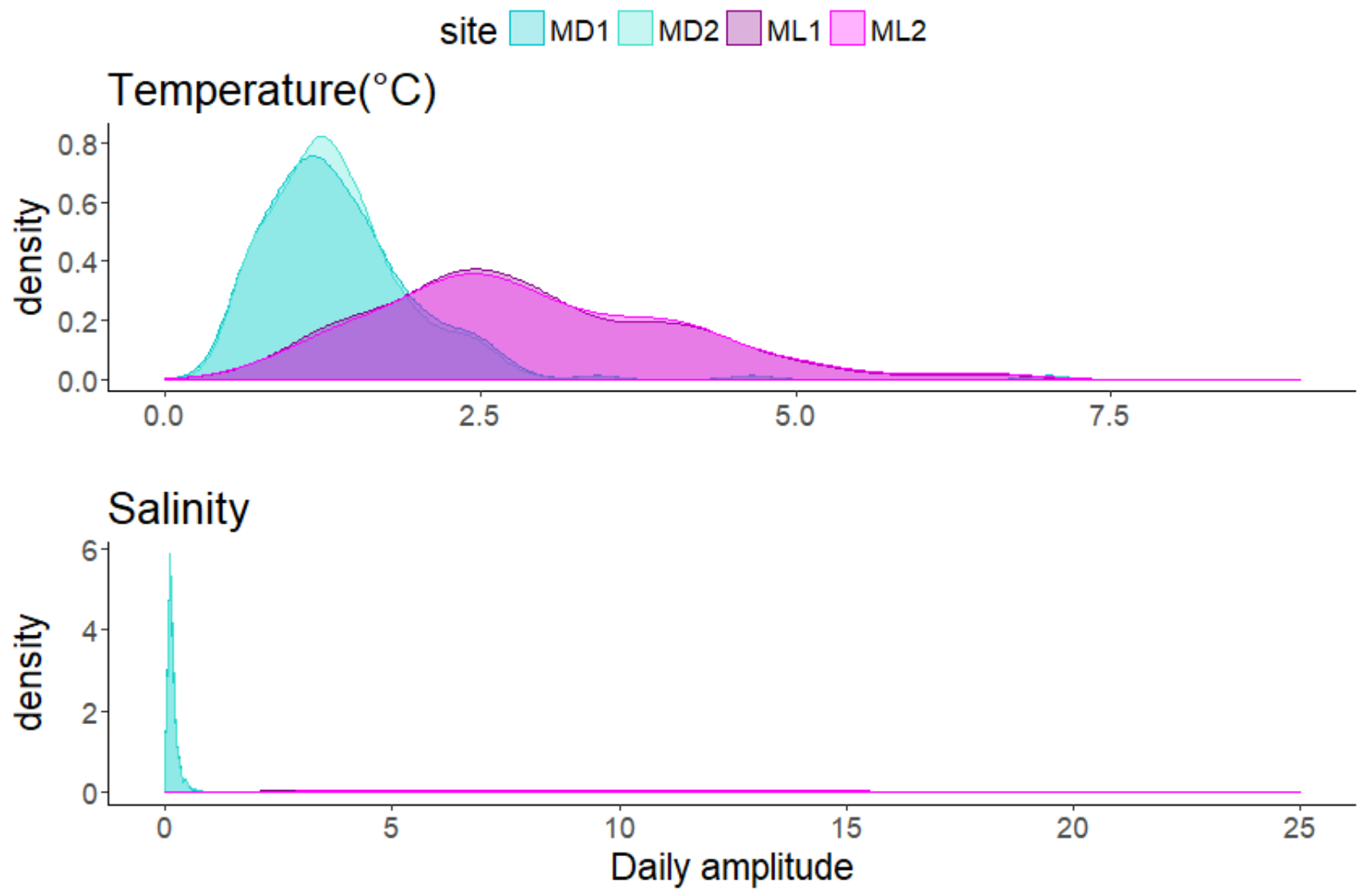

Fig. 5 Frequency plot of the temperature and salinity daily amplitude (max-min) in Mdloti (MD) and Mlalazi (ML) estuaries measured at the mouth (1) and upstream (2) from January to November 2017. 


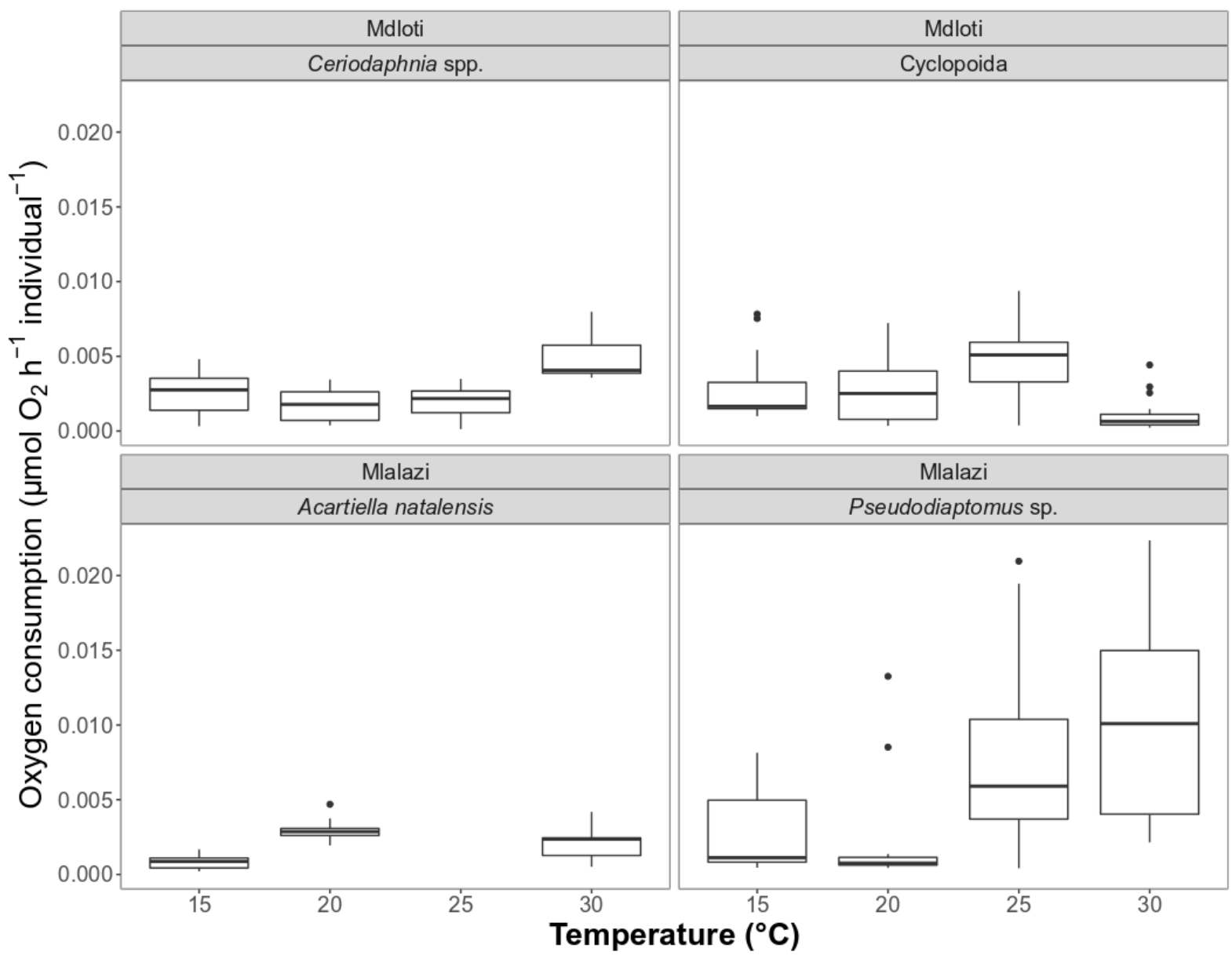

Fig. 6 Boxplot of hourly oxygen respiration rates per individual of the four representative taxa, at different temperatures, at the two estuaries, Mdloti and Mlalazi (the box represent the upper and lower quartiles, the line represent the median, the whiskers shows the min and max values (1.5*interquartile range) and the dots represents the outliers). 


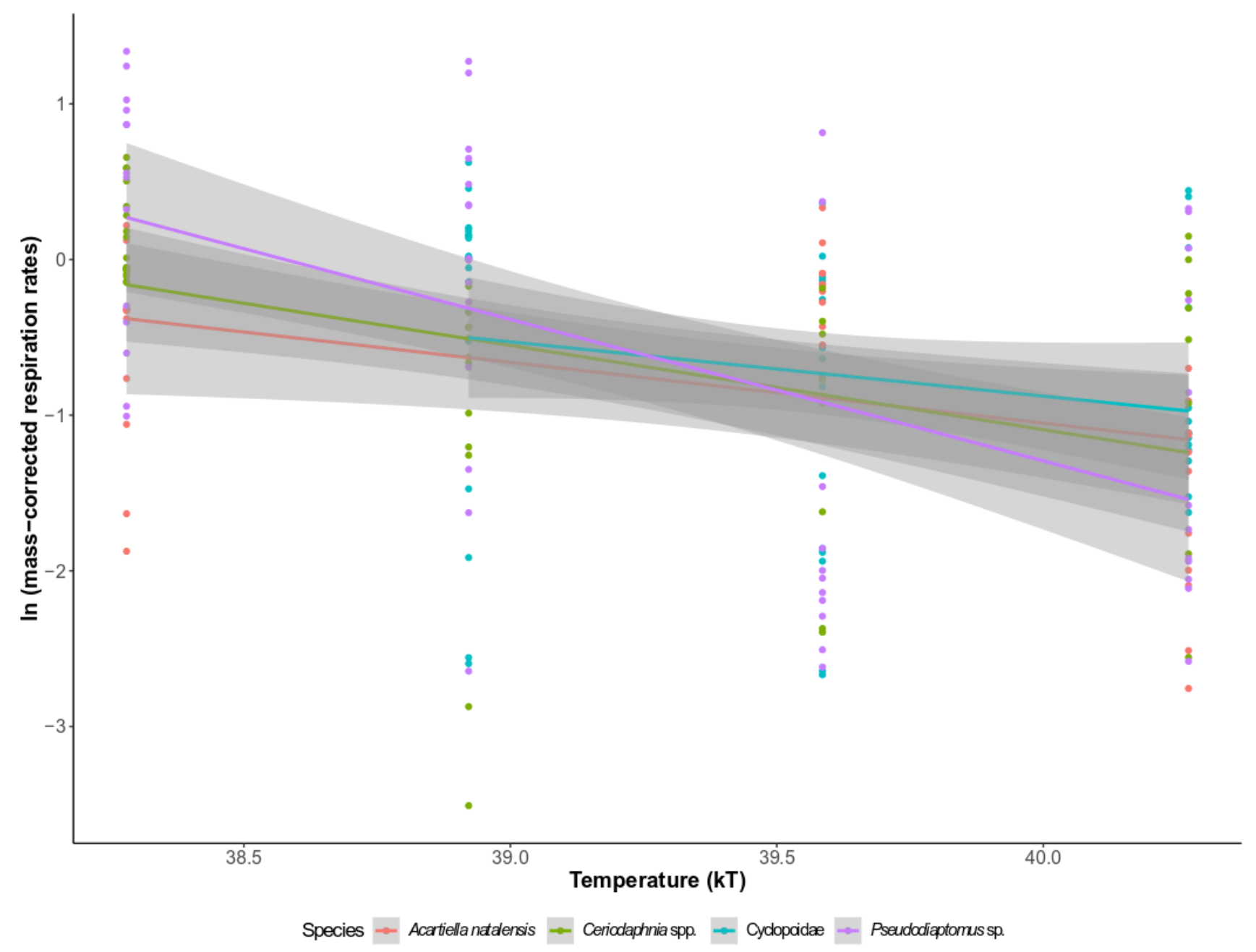

Fig. 7 Temperature dependence of the mass-corrected respiration rates for each taxon. The temperature is expressed as the inverse of absolute temperature $(K)$ multiplied by the Boltzmann's constant $(0.0000862 \mathrm{eV}$ K-1). The natural logarithm of the mass corrected respiration rate in the $\mathrm{Y}$-axis was calculated by dividing the respiration rate ( $\mu \mathrm{mol} 02 \mathrm{~h}-1$ animal1) by the biomass (DW, g) raised to the empirically determined scaling exponent of 0.43 . The grey band around the regression lines represent the $95 \%$ confidence interval. 